\title{
Emergent Early Markers of Renal Progression in Autosomal-Dominant Polycystic Kidney Disease Patients: Implications for Prevention and Treatment
}

\author{
Imed Helal Berenice Reed Robert W. Schrier \\ Division of Renal Diseases and Hypertension, University of Colorado Denver, Aurora, Colo., USA
}

\section{Key Words}

Autosomal-dominant polycystic kidney disease $\cdot$ Kidney volume $\cdot$ Hyperfiltration $\cdot$ Renal blood flow

\begin{abstract}
Autosomal-dominant polycystic kidney disease (ADPKD) is the most common single cause of end-stage renal disease after diabetes, hypertension and glomerulonephritis. The clinical course of ADPKD is highly variable. Even with optimal care and therapy monitoring, currently the progression of ADPKD is slowed but not stopped. Newer treatments will no doubt become available in the future, but their side effect profiles will always need to be considered. Therefore, markers to distinguish ADPKD patients with a poor versus a good prognosis will be helpful. Several risk factors influencing kidney disease progression in ADPKD have been identified in the current era. The present review will discuss the spectrum of early markers of ADPKD renal disease progression. Specifically, the volume of total kidney, hypertension, glomerular hyperfiltration, renal blood flow, microalbuminuria, uric acid, and urinary molecular markers will be discussed. On this background, implications for the prevention and treatment of kidney disease progression in ADPKD are also discussed.

Copyright $\odot 2012$ S. Karger AG, Basel
\end{abstract}

\section{Introduction}

Autosomal-dominant polycystic kidney disease (ADPKD) is the primary genetic cause of kidney disease and the 4th most common cause of end-stage renal disease (ESRD) after diabetes, hypertension and glomerulonephritis $[1,2]$. ADPKD constitutes $2.3 \%$ of patients on chronic dialysis [2], and may present with a faster decline in glomerular filtration rate (GFR) than other renal diseases [3]. The clinical course of ADPKD is highly variable, and progression to ESRD occurs between the 4th and 6th decades [4], although severe disease may occur in children [5]. In adults with ADPKD, several risk factors for faster progression have been identified, including PKD-1 gene mutation, male gender, young age at diagnosis, presence of hypertension, hematuria, proteinuria, and young age at onset of hypertension [4-7].

Early onset of hypertension, even in childhood, has been found to occur in ADPKD [8]. Moreover, compared to matched patients with essential hypertension, plasma renin activity and aldosterone are more stimulated in hypertensive ADPKD patients [9]. Furthermore, all components of the renin-angiotensin system (RAS) have been found in ADPKD kidneys [10]. With the availability of RAS inhibitors, these agents have become the initial ther-

\section{KARGER}

Fax +4161306 1234

E-Mail karger@karger.ch

www.karger.com (c) 2012 S. Karger AG, Basel

$0250-8095 / 12 / 0362-0162 \$ 38.00 / 0$

Accessible online at:

www.karger.com/ajn
Robert W. Schrier

University of Colorado Denver, Division of Renal Diseases and Hypertension

Box C-281, 1270 East 19th, RC2 7th floor, Room 7001

Aurora, CO 80045 (USA)

Tel. +1 303724 4837, E-Mail Robert.schrier@ucdenver.edu 
Fig. 1. Mechanisms of ADPKD.

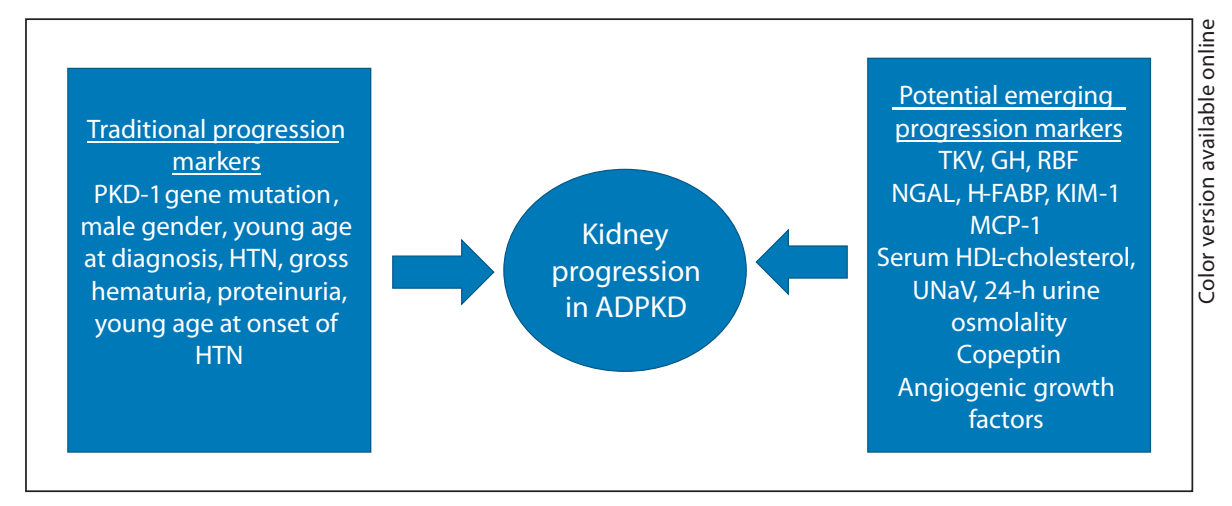

apy in treating hypertension in ADPKD. While cause and effect remains to be proven, there are several epidemiological studies which demonstrate improved prognosis in ADPKD in association with better control of hypertension and RAS inhibition $[11,12]$. Nevertheless, even with this improved care which has been associated with later progression to ESRD [11] and improved survival [12] in ADPKD, there is a great need to identify early risk factors and more definitive treatment.

Currently, kidney function in ADPKD patients is monitored by observing changes in serum creatinine and estimated GFR. However, kidney function may remain preserved until the 4th to 6th decade of life, when advanced renal cystic involvement has occurred. Clinical markers are therefore needed to identify the early progression of ADPKD. Recent advances have led to greater understanding of the mechanisms of ADPKD and several potential early markers have been found to be associated with renal disease progression (fig. 1).

\section{Total Kidney Volume}

ADPKD is a systemic disorder characterized by gross enlargement of the kidneys over time due to multiple cysts that originate from the tubular epithelium of the nephrons. Recent evidence indicates that the progressive increase in kidney volume in patients with ADPKD is primarily due to the accumulation of fluid within innumerable cysts and the proliferation of mural epithelial cells $[13,14]$. It is evident that kidneys of patients with ADPKD progressively increase in volume beginning at birth and progress through life. [14]. According to several cross-sectional and longitudinal human studies, an inverse correlation between GFR and total kidney volume (TKV) has been described [3, 15-17]. The Consortium for
Radiologic Imaging Studies of Polycystic Kidney Disease study (CRISP) funded by the National Institutes of Health was established to develop methods that reliably measure disease progression in ADPKD over a relatively short period of time [15]. The CRISP cohort confirmed with MRI that cystic growth and renal enlargement is significant prior to impairment of renal function [15], as had been shown with renal ultrasound [16]. The CRISP cohort also revealed that normotensive patients have smaller cyst and renal volumes compared to hypertensive counterparts [15]. Renal ultrasound studies in children have also demonstrated this relationship between kidney volumes and blood pressure [8]. Longitudinal studies of animal models support the hypothesis that reducing the rate of kidney volume enlargement may improve kidney prognosis in ADPKD patients [14].

Noninvasive radiologic methods have therefore been developed to monitor the rates of renal cyst and volume enlargement in ADPKD patients [18, 19]. Thus, it has been proposed that TKV can be used as a marker of ADPKD progression. For clinicians, incorporating measurements of TKV by ultrasonography [16], computed tomography [18] or MRI [15] may allow prediction of the kidney enlargement rate of ADPKD patients [3, 20]. Moreover, intervals as short as 6-12 months between measurements may be adequate to determine an effect of treatment to reduce the rate of kidney volume progression [21]. Estimating the growth rate of TKV therefore can be important in stratifying at-risk ADPKD patients $[16,20]$. The patients with the more rapid kidney enlargement should be monitored more frequently and receive optimal care, including blood pressure control. There is a prospective, randomized study in hypertensive ADPKD patients which demonstrated that reversal of left ventricular hypertrophy was significantly better with a blood pressure goal of less than $120 / 80 \mathrm{~mm} \mathrm{Hg}$ as compared to $140 / 90 \mathrm{~mm} \mathrm{Hg}$ [22]. 
The Food and Drug Administration co-organized a scientific workshop with the Polycystic Kidney Disease Foundation to discuss and identify potential markers of disease progression in ADPKD. While effects of any new ADPKD treatment on kidney volume may occur earlier than diminished renal function, TKV is considered a surrogate endpoint while seru $\mathrm{m}$ creatinine and GFR are considered harder endpoints.

\section{Hypertension}

Hypertension may occur in children with ADPKD [8] and recent evidence suggests that early treatment may be necessary to dramatically change the course of ADPKD [8]. In a randomized study in ADPKD children with borderline hypertension (75th to 95th percentiles), control of blood pressure with an angiotensin-converting enzyme inhibitor stabilized kidney function and left ventricular mass compared to untreated children [8]. In ADPKD adults, however, $80-90 \%$ are already hypertensive, therefore blood pressure cannot be used as an early marker of renal progression [11]. The $10-20 \%$ of ADPKD adults without hypertension can, however, have a much better prognosis than the hypertensive ADPKD patients [11].

\section{Glomerular Hyperfiltration}

As noted, most patients with ADPKD have renal function which remains within the normal range for several decades, despite progressive renal enlargement [14]. This phenomenon is related to compensatory glomerular hyperfiltration $(\mathrm{GH})$ in surviving nephrons. Serum creatinine levels only start to rise appreciably above baseline when more than $50 \%$ of functioning parenchyma has been destroyed. Thus, waiting to intervene in ADPKD once the serum creatinine begins to rise may not be optimal. Moreover, this is a time when GH may be damaging the remaining nephrons secondary to glomerular hypertension. There are very few studies that have examined $\mathrm{GH}$ in patients with ADPKD, but GH has been proposed to be a potential early clinical marker of ADPKD [23, 24]. A recent study demonstrated that young adults with ADPKD have an increased filtration fraction, which is compatible with GH [25]. Recently, we have shown in a longitudinal study that $\mathrm{GH}$ ( $\mathrm{GH}$ defined as creatinine clearance $\geq 140 \mathrm{ml} / \mathrm{min} / 1.73 \mathrm{~m}^{2}$ ) is associated with a faster rate of renal function decline and an increased rate of kidney enlargement in children with ADPKD [26]. Thus,
$\mathrm{GH}$, combined with increased $\mathrm{TKV}$, may be used as an early marker for more severe progression of ADPKD in children.

Identifying $\mathrm{GH}$ as a risk factor for renal progression in ADPKD patients could enable early intervention. GH in ADPKD children may be attenuated by blocking the vasoconstriction of the glomerular efferent arteriole by angiotensin II. This could reverse the glomerular hypertension associated with GH. A future prospective randomized interventional study is needed to compare RAS blockers with placebo in ADPKD children with GH.

\section{Uric Acid}

Increases in serum uric acid level have been shown to be a harbinger of renal progression in patients with chronic kidney disease (CKD) [27]. Moreover, there are experimental results which suggest that uric acid is not just a marker of hypertension, but is a pathological factor involved activation of the RAS [28]. In a recent study of over 800 ADKPD patients, we have shown in a multivariate analysis that increased uric acid correlates independently with hypertension and renal progression [unpubl. data].

\section{Renal Blood Flow}

Measurement of renal blood flow (RBF) is useful for assessment of renal function in a variety of renal disorders. A reduction in RBF occurs early and may precede the development of hypertension [29] and also has been found in the early stages of disease in ADPKD patients [30-32]. Activation of the RAS [33, 34], increased sympathetic activity [35], enhanced synthesis of endothelin [3537], and impaired production of nitric oxide [38] may contribute not only to hypertension in ADPKD patients, but also to renal vasoconstriction, remodeling of the microcirculation, and development of chronic kidney disease. Recent improvements in MRI technology have allowed for precise determinations of RBF with single breath hold MRI acquisitions [39]. MRI measurements of $\mathrm{RBF}$ therefore were analyzed with respect to progression of ADPKD. The CRISP study demonstrated that RBF is reduced early in ADPKD, before loss of renal function, and is associated with increased TKV [15, 40, 41]. Moreover, in a recent study a decrease in $\mathrm{RBF}$ was observed in young adults with ADPKD [25]. 
Thus, RBF may be a more sensitive index of early disease progression than changes in GFR and perhaps even TKV. MRI measurements of RBF, therefore, deserve further consideration as a potential surrogate marker of renal progression in ADPKD patients.

\section{Urine and Blood Emergent Early Markers}

Measurement of RBF and TKV is time consuming and expensive. Therefore, interest has grown in urinary and blood biomarkers. These biomarkers are relatively easy to obtain and inexpensive to measure. Because ADPKD is a disease characterized by structural abnormalities of renal tubules, interstitial inflammation and fibrosis, urinary biomarkers reflecting tubular damage and inflammation could be promising candidate markers to assess disease severity. On cross-sectional analysis [42] in ADPKD patients, RBF and GFR values were associated with urinary excretion of $\beta_{2}$-microglobulin, neutrophil gelatinase-associated lipocalin (NGAL), and heart-type fatty acidbinding protein (H-FABP) independent of urine albumin excretion (UAE). TKV was associated with kidney injury molecule-1 (KIM-1), NGAL, and monocyte chemotactic protein-1 (MCP-1) independent of UAE. Another study identified a unique urinary biomarker profile in patients with ADPKD [43]. Thus, these urinary biomarkers could be of value for determination of disease severity in patients with ADPKD.

Arginine vasopressin (AVP), or antidiuretic hormone $(\mathrm{ADH})$, is a neurohypophysial hormone which increases water permeability of kidney collecting duct. Vasopressin promotes CAMP production by acting on V2 receptors in the distal nephron and collecting ducts. Experimental studies have suggested an important role for cAMP in promoting cyst growth in ADPKD [44]. In experimental studies, cAMP stimulated cyst formation by promoting chloride-driven fluid secretion and by stimulating activation and proliferation of cyst-derived cells [45]. The potential role of vasopressin was confirmed by the findings in animal models of ADPKD, in which blocking the effect of vasopressin by a pharmacologic agent $[19,45-48]$ or by drinking more water [49] led to reduction of cyst formation and renal function preservation. On cross-sectional analysis [50], investigators demonstrated that copeptin, a surrogate marker of vasopressin, was associated with disease severity in ADPKD patients. These results suggest that vasopressin antagonists may have a protective effect in ADPKD. The TEMPO study is evaluating this possibility and is near completion [47]. Secreted frizzled-relat- ed protein 4 (sFRP4) is up-regulated in human ADPKD and is detected in the urine. [51]. Antagonism of the vasopressin 2 receptor (V2R) blocks tubular sFRP4 expression. Therefore, this protein may be a potential biomarker for monitoring the progression of ADPKD.

It is apparent that vascular changes and remodeling must occur in order to support the massive growth of cysts in ADPKD patients. Angiogenesis has been implicated in the pathogenesis of renal cyst growth in ADPKD $[52,53]$. Moreover, the identification of angiogenic growth factors, such as vascular endothelial growth factor, in the fluid from both human renal and hepatic cysts [52, 54], and up-regulated expression of angiopoietin-1 and -2 , and their endothelial tyrosine kinase-2 receptor in ADPKD cholangiocytes supports a role of angiogenic growth factors in mediating angiogenesis in ADPKD [55]. Recently, it was shown that angiogenic growth factors significantly correlated with structural change in both the kidney and the heart as well as with urinary protein excretion [56]. Thus, the correlation between angiogenic growth factors with both renal and cardiac disease severity supports a possible role for angiogenesis in the early progression of disease in ADPKD.

A recent study has identified three potentially modifiable factors that may influence the clinical course of ADPKD [57]. Lower serum HDL-cholesterol, increased urine sodium excretion and higher 24-hour urine osmolality at baseline was associated with increased cyst growth and kidney progression in ADPKD patients [57].

\section{Summary and Future Perspectives}

A better understanding of the pathophysiology of the ADPKD and the availability of animal models has identified promising early markers of renal progression. Several clinical, imaging, urine and blood markers have been associated with renal progression in ADPKD. These markers may be useful tools in clinical practice in the future. Recognizing these emergent early markers may identify high-risk ADPKD patients and allow more intensive intervention. To date, however, it is not known whether these markers are primarily determined by renal function progression or whether these markers are factors in causing loss of renal function. Prospective, randomized studies in ADPKD will be necessary to determine whether these factors are merely markers of disease progression or are active pathogenetic factors in the progression of ADPKD. 


\section{Acknowledgements}

I.H. has received an International Society of Nephrologyfunded fellowship and support from the Laboratory of Kidney Pathology (LR00SP01-Pr Ben Maiz Hedi), Charles Nicolle Hospital, Tunis, Tunisia.

This research was supported by the Zell Family Foundation.

\section{Disclosure Statement}

None of the authors have a conflict of interest to declare.

\section{References}

1 Iglesias C, Torres V, Offord K, Holley K, Beard C, Kurland L: Epidemiology of adult polycystic kidney disease, Olmsted County, Minnesota: 1935-1980. Am J Kidney Dis 1983;2:630-639.

2 US Renal Data System: USRDS 2011. Annual Data Report, 2011.

- 3 Grantham JJ, Torres VE, Chapman AB, Guay-Woodford LM, Bae KT, King BF Jr, Wetzel LH, Baumgarten DA, Kenney PJ, Harris PC, Klahr S, Bennett WM, Hirschman GN, Meyers CM, Zhang X, Zhu F, Miller JP, CRISP Investigators: Volume progression in polycystic kidney disease. N Engl J Med 2006;354:2122-2130.

-4 Gabow PA, Johnson AM, Kaehny WD, Kimberling WJ, Lezotte DC, Duley IT, Jones RH: Factors affecting the progression of renal disease in autosomal-dominant polycystic kidney disease. Kidney Int 1992;41:1311 1319.

5 Johnson AM, Gabow PA: Identification of patients with autosomal dominant polycystic kidney disease at highest risk for endstage renal disease. J Am Soc Nephrol 1997; 8:1560-1567.

-6 Choukroun G, Itakura Y, Albouze G, Christophe JL, Man NK, Grünfeld JP, Jungers P: Factors influencing progression of renal failure in autosomal dominant polycystic kidney disease. J Am Soc Nephrol 1995;6:16341642.

-7 Chapman AB, Johnson AM, Gabow PA, Schrier RW: Overt proteinuria and microalbuminuria in autosomal dominant polycystic kidney disease. J Am Soc Nephrol 1994;5: 1349-1354.

-8 Cadnapaphornchai MA, McFann K, Strain JD, Masoumi A, Schrier RW: Prospective change in renal volume and function in children with ADPKD. Clin J Am Soc Nephrol 2009;4:820-829.

-9 Chapman AB, Johnson A, Gabow PA, Schrier RW: The renin-angiotensin-aldosterone system and autosomal dominant polycystic kidney disease. N Engl J Med 1990;323:10911096.

-10 Loghman-Adham M, Soto CE, Inagami T, Cassis L: The intrarenal renin-angiotensin system in autosomal dominant polycystic kidney disease. Am J Physiol Renal Physiol 2004;287:775-788.
1 Schrier RW, McFann KK, Johnson AM: Epidemiological study of kidney survival in autosomal dominant polycystic kidney disease. Kidney Int 2003;63:678-685.

12 Patch C, Charlton J, Roderick PJ, Gulliford MC: Use of antihypertensive medications and mortality of patients with autosomal dominant polycystic kidney disease: a population-based study. Am J Kidney Dis 2011;57: 856-862.

13 Grantham JJ: The etiology, pathogenesis, and treatment of autosomal dominant polycystic kidney disease: recent advances. Am J Kidney Dis 1996;28:788-803.

14 Ecder T, Fick-Brosnahan GM, Schrier RW: Polycystic kidney disease; in Schrier RW (ed): Diseases of the Kidney and Urinary Tract, ed 8. Philadelphia, Lippincott Williams \& Wilkins, 2007, pp 502-539.

15 Chapman AB, Guay-Woodford LM, Grantham JJ, Torres VE, Bae KT, Baumgarten DA, Kenney PJ, King BF Jr, Glockner JF, Wetzel LH, Brummer ME, O'Neill WC, Robbin ML, Bennett WM, Klahr S, Hirschman GH, Kimmel PL, Thompson PA, Miller JP , Consortium for Radiologic Imaging Studies of Polycystic Kidney Disease cohort: Renal structure in early autosomal-dominant polycystic kidney disease (ADPKD): the consortium for radiologic imaging studies of polycystic kidney disease (CRISP) cohort. Kidney Int 2003;64:1035-1045.

16 Fick-Brosnahan GM, Belz MM, McFann KK, Johnson AM, Schrier RW: Relationship between renal volume growth and renal function in autosomal dominant polycystic kidney disease: a longitudinal study. Am J Kidney Dis 2002;39:1127-1134.

17 Schrier RW: Renal volume, renin-angiotensin-aldosterone system, hypertension, and left ventricular hypertrophy in patients with autosomal dominant polycystic kidney disease. J Am Soc Nephrol 2009;20:1888-1893.

18 Sise C, Kusaka M, Wetzel LH, Winklhofer F, Cowley BD, Cook LT, Gordon M, Grantham $\mathrm{JJ}$ : Volumetric determination of progression in autosomal dominant polycystic kidney disease by computed tomography. Kidney Int 2000;58:2492-2501.
9 King BF, Reed JE, Bergstralh EJ, Sheedy PF 2nd, Torres VE: Quantification and longitudinal trends of kidney, renal cyst, and renal parenchyma volumes in autosomal dominant polycystic kidney disease. J Am Soc Nephrol 2000;11:1505-1511.

20 Bae KT, Grantham JJ: Imaging for the prognosis of autosomal dominant polycystic kidney disease. Nat Rev Nephrol 2010;6:96-106.

-21 Ruggenenti P, Remuzzi A, Ondei P, Fasolini G, Antiga L, Ene-Iordache B, Remuzzi G, Epstein FH: Safety and efficacy of long-acting somatostatin treatment in autosomaldominant polycystic kidney disease. Kidney Int 2005;68:206-216.

22 Schrier R, McFann K, Johnson A, Chapman A, Edelstein C, Brosnahan G, Ecder T, Tison L: Cardiac and renal effects of standard versus rigorous blood pressure control in autosomal-dominant polycystic kidney disease: results of a seven-year prospective randomized study. J Am Soc Nephrol 2002;13:17331739.

23 Dimitrakov D, Kumchev E, Lyutakova E, Grigorov L: Glomerular hyperfiltration and serum beta 2 -microglobulin used as early markers in diagnosis of autosomal dominant polycystic kidney disease. Folia Med (Plovdiv) 1993;35:59-62.

24 Wong H, Vivian L, Weiler G, Filler G: Patients with autosomal dominant polycystic kidney disease hyperfiltrate early in their disease. Am J Kidney Dis 2004;43:624-628.

25 Meijer E, Rook M, Tent H, Navis G, van der Jagt EJ, de Jong PE, Gansevoort RT: Early renal abnormalities in autosomal dominant polycystic kidney disease. Clin J Am Soc Nephrol 2010;5:1091-1098.

26 Helal I, Reed B, McFann K, Yan XD, FickBrosnahan GM, Cadnapaphornchai $M$, Schrier RW: Glomerular hyperfiltration and renal progression in children with autosomal dominant polycystic kidney disease. Clin J Am Soc Nephrol 2011;6:2439-2443.

27 Chonchol M, Shlipak MG, Katz R, Sarnak MJ, Newman AB, Siscovick DS, Kestenbaum B, Carney JK, Fried LF: Relationship of uric acid with progression of kidney disease. Am J Kidney Dis 2007;50:239-247. 
$\checkmark 28$ Corry DB, Eslami P, Yamamoto K, Nyby MD, Makino H, Tuck ML: Uric acid stimulates vascular smooth muscle cell proliferation and oxidative stress via the vascular renin-angiotensin system. J Hypertens 2008; 26:269-275.

-29 Barrett BJ, Foley R, Morgan J, Hefferton D, Parfrey P: Differences in hormonal and renal vascular responses between normotensive patients with autosomal dominant polycystic kidney disease and unaffected family members. Kidney Int 1994;46:1118-1123.

- 30 Chapman AB, Johnson A, Gabow PA, Schrier RW: The renin-angiotensin-aldosterone system and autosomal dominant polycystic kidney disease. N Engl J Med 1990;323:10911096.

-31 Torres VE, Wilson DM, Burnett JC Jr, Johnson CM, Offord KP: Effect of inhibition of converting enzyme on renal hemodynamics and sodium management in polycystic kidney disease. Mayo Clin Proc 1991;66:10101017.

- 32 Watson ML, Macnicol AM, Allan PL, Wright AF: Effects of angiotensin converting enzyme inhibition in adult polycystic kidney disease. Kidney Int 1992;41:206-210.

-33 Graham PC, Lindop GB: The anatomy of the renin-secreting cell in adult polycystic kidney disease. Kidney Int 1988;33:1084-1090.

- 34 Torres VE, Donovan KA, Scicli G, Holley KE, Thibodeau SN, Carretero OA, Inagami T, McAteer JA, Johnson CM: Synthesis of renin by tubulocystic epithelium in autosomal-dominant polycystic kidney disease. Kidney Int 1992;42:364-373.

- 35 Cerasola G, Vecchi M, Mulè G, Cottone S, Mangano MT, Andronico G, Contorno A, Parrino I, Renda F, Pavone G: Sympathetic activity and blood pressure pattern in autosomal dominant polycystic kidney disease hypertensives. Am J Nephrol 1998;18:391398.

- 36 Hocher B, Zart R, Schwarz A, Vogt V, Braun C, Thöne-Reineke C, Braun N, Neumayer $\mathrm{HH}$, Koppenhagen K, Bauer C, Rohmeiss P: Renal endothelin system in polycystic kidney disease. J Am Soc Nephrol 1998;9:11691177.

- 37 Giusti R, Neri M, Angelini D, Carlini A, Fiorini I, Bigongiari P, Antonelli A: Plasma concentration of endothelin and arterial pressure in patients with ADPKD. Contrib Nephrol. Basel, Karger, 1995, vol 115, pp 118121.

- 38 Wang D, Iversen J, Strandgaard S: Endothelium-dependent relaxation of small resistance vessels is impaired in patients with autosomal dominant polycystic kidney disease. J Am Soc Nephrol 2000;11:1371-1376.

- 39 Sommer G, Corrigan G, Fredrickson J, Sawyer-Glover A, Liao JR, Myers B, Pelc N: Renal blood flow: measurement in vivo with rapid spiral MR imaging. Radiology 1998;208: 729-734.
40 King BF, Torres VE, Brummer ME, Chapman AB, Bae KT, Glockner JF, Arya K, Felmlee JP, Grantham JJ, Guay-Woodford LM, Bennett WM, Klahr S, Hirschman GH, Kimmel PL, Thompson PA, Miller JP; Consortium for Radiologic Imaging Studies of Polycystic Kidney Disease (CRISP): Magnetic resonance measurements of renal blood flow as a marker of disease severity in autosomaldominant polycystic kidney disease. Kidney Int 2003;64:2214-2221.

41 Torres VE, King BF, Chapman AB, Brummer ME, Bae KT, Glockner JF, Arya K, Risk D, Felmlee JP, Grantham JJ, Guay-Woodford LM, Bennett WM, Klahr S, Meyers CM, Zhang X, Thompson PA, Miller JP, Consortium for Radiologic Imaging Studies of Polycystic Kidney Disease (CRISP): Magnetic resonance measurements of renal blood flow and disease progression in autosomal dominant polycystic kidney disease. Clin J Am Soc Nephrol 2007;2:112-120.

42 Meijer E, Boertien WE, Nauta FL, Bakker SJ, van Oeveren W, Rook M, van der Jagt EJ, van Goor H, Peters DJ, Navis G, de Jong PE, Gansevoort RT: Association of urinary biomarkers with disease severity in patients with autosomal dominant polycystic kidney disease: a cross-sectional analysis. Am J Kidney Dis 2010;56:883-895.

43 Kistler AD, Mischak H, Poster D, Dakna M, Wüthrich RP, Serra AL: Identification of a unique urinary biomarker profile in patients with autosomal dominant polycystic kidney disease. Kidney Int 2009;76:89-96.

44 Grantham JJ: Lillian Jean Kaplan International Prize for advancement in the understanding of polycystic kidney disease. Understanding polycystic kidney disease: a systems biology approach. Kidney Int 2003;64: 1157-1162.

45 Belibi FA, Reif G, Wallace DP, Yamaguchi T, Olsen L, Li H, Helmkamp GM Jr, Grantham JJ: Cyclic AMP promotes growth and secretion in human polycystic kidney epithelial cells. Kidney Int 2004;66:964-973.

46 Gattone VH 2nd, Wang X, Harris PC, Torres VE: Inhibition of renal cystic disease development and progression by a vasopressin V2 receptor antagonist. Nat Med 2003;9:13231326.

47 Torres VE, Meijer E, Bae KT, Chapman AB, Devuyst O, Gansevoort RT, Grantham JJ, Higashihara E, Perrone RD, Krasa HB, Ouyang JJ, Czerwiec FS: Rationale and design of the TEMPO (Tolvaptan Efficacy and Safety in Management of Autosomal Dominant Polycystic Kidney Disease and its Outcomes) 3-4 study. Am J Kidney Dis 2011;57:692699.
48 Higashihara E, Torres VE, Chapman AB, Grantham JJ, Bae K, Watnick TJ, Horie S, Nutahara K, Ouyang J, Krasa HB, Czerwiec FS; TEMPO Formula and 156-05-002 Study Investigators: Tolvaptan in autosomal dominant polycystic kidney disease: three years' experience. Clin J Am Soc Nephrol 2011;6: 2499-2507.

49 Nagao S, Nishii K, Katsuyama M, Kurahashi $\mathrm{H}$, Marunouchi T, Takahashi H, Wallace DP: Increased water intake decreases progression of polycystic kidney disease in the PCK rat. J Am Soc Nephrol 2006; 17:2220-2227.

50 Meijer E, Bakker SJ, van der Jagt EJ, Navis G, de Jong PE, Struck J, Gansevoort RT: Copeptin, a surrogate marker of vasopressin, is associated with disease severity in autosomal dominant polycystic kidney disease. Clin J Am Soc Nephrol 2011;6:361-368.

51 Romaker D, Puetz M, Teschner S, Donauer J, Geyer M, Gerke P, Rumberger B, Dworniczak B, Pennekamp P, Buchholz B, Neumann HP, Kumar R, Gloy J, Eckardt KU, Walz G: Increased expression of secreted frizzled-related protein 4 in polycystic kidneys. J Am Soc Nephrol 2009;20:48-56.

52 Bello-Reuss E, Holubec K, Rajaraman S: Angiogenesis in autosomal-dominant polycystic kidney disease. Kidney Int 2001;60:3745.

53 Wei W, Popov V, Walocha JA, Wen J, BelloReuss E: Evidence of angiogenesis and microvascular regression in autosomal-dominant polycystic kidney disease kidneys: a corrosion cast study. Kidney Int 2006;70: 1261-1268.

54 Nichols MT, Gidey E, Matzakos T, Dahl R, Stiegmann G, Shah RJ, Grantham JJ, Fitz JG, Doctor RB: Secretion of cytokines and growth factors into autosomal dominant polycystic kidney disease liver cyst fluid. Hepatology 2004;40:836-846.

55 Fabris L, Cadamuro M, Fiorotto R, Roskams T, Spirlì C, Melero S, Sonzogni A, Joplin RE, Okolicsanyi L, Strazzabosco M: Effects of angiogenic factor overexpression by human and rodent cholangiocytes in polycystic liver diseases. Hepatology 2006;43:1001-1012.

-56 Reed BY, Masoumi A, Elhassan E, McFann K, Cadnapaphornchai MA, Maahs DM, Snell-Bergeon JK, Schrier RW: Angiogenic growth factors correlate with disease severity in young patients with autosomal dominant polycystic kidney disease. Kidney Int 2011;79:128-134.

57 Torres VE, Grantham JJ, Chapman AB, Mrug M, Bae KT, King BF Jr, Wetzel LH, Martin D, Lockhart ME, Bennett WM, Moxey-Mims M, Abebe KZ, Lin Y, Bost JE, Consortium for Radiologic Imaging Studies of Polycystic Kidney Disease (CRISP): Potentially modifiable factors affecting the progression of autosomal dominant polycystic kidney disease. Clin J Am Soc Nephrol 2011; 6:640-647. 